\title{
A Single-Reset-Integrator-Based Implementation of Line-Current-Shaping Controller for High-Power-Factor Operation of Flyback Rectifier
}

\author{
Souvik Chattopadhyay and V. Ramanarayanan
}

\begin{abstract}
The objective of this paper is to present a simple yet accurate implementation of a resistor-emulator-type line-currentshaping controller for high-power-factor operation of a flyback rectifier. The important feature is that input voltage sensing is not required. In the circuit realization of the controller, no multiplier is used. Current shaping is performed directly on the input filter inductor current. The modulator uses only one reset integrator for the generation of duty ratio. The analysis presented in this paper shows the effect of input filter capacitance on discontinuous conduction mode of operation of the flyback inductor. Design equations for selection of the input filter components are derived. A low-frequency small-signal model of the rectifier is developed and verified by measurement up to $1 \mathrm{kHz}$. The performance of the controller is first tested by the SABER circuit simulator package. Then, a 100-W 110-V ac input 50-V dc output single-phase flyback rectifier prototype is built for experimental verification.
\end{abstract}

Index Terms-Current-mode control, discontinuous-conduction-mode operation, flyback rectifier, high-power-factor rectifiers, power-factor correction.

\section{INTRODUCTION}

$\mathbf{F}$ OR HIGH-POWER-FACTOR operation of the flyback rectifier in the continuous conduction mode (CCM), nonlinear carrier (NLC) control [1] offers the advantage of simpler control structure compared to other CCM techniques, such as average current mode [2] or charge control [3]. The key function of the NLC controller is the generation of the carrier waveform based on the expression of the average switch current in every switching period. For the flyback rectifier, the ideal carrier waveform is approximated with the exponential carrier waveform to achieve simplicity in hardware implementation. As a result of the approximate carrier waveform, the input current is not exactly equal to the ideal $i_{g}=v_{g} / R_{e}$. The control technique that is proposed in [4] is simple, requires only one reset integrator, and is suitable for implementation as a smart-power integration scheme. This avoids the approxima-

Paper IPCSD 01-089, presented at the 2001 Industry Applications Society Annual Meeting, Chicago, IL, September 30-October 5, and approved for publication in the IEEE TRANSACTIONS ON INDUSTRY APPLICATIONS by the Industrial Power Converter Committee of the IEEE Industry Applications Society. Manuscript submitted for review August 1, 2001 and released for publication January 18, 2002.

The authors are with the Department of Electrical Engineering, Indian Institute of Science, Bangalore 560012, India (e-mail: souvik@ee.iisc.ernet.in; vram@ee.iisc.ernet.in).

Publisher Item Identifier S 0093-9994(02)02867-0. tion in the carrier waveform by rearranging the same control equation as used in [1]. However, this implementation is also not exact, as the switch current, instead of the input current, is integrated over a switching cycle. A more exact method of implementation is proposed here as the carrier waveform is not approximated and, instead of the switch current, the input current is integrated. Only one reset integrator is required for input current shaping without sensing the input voltage in the CCM.

In Section II, we explain the principle of operation of the proposed controller with the circuit diagram of the flyback rectifier shown in Fig. 1. The condition for discontinuous conduction mode (DCM) of operation is derived in Section III. A comparison between DCM and CCM methods of input current shaping is provided in Section IV. The design equations for the selection of input filter components are formulated in Section V. The steady-state stability condition has been derived in Section VI. The results of SABER simulation of the flyback rectifier with the proposed controller are presented in Section VII. In Section VIII, a small-signal model of the rectifier is derived and control to output transfer function is experimentally verified. In Section IX, the experimental results of the prototype converter are presented.

\section{INPUT-CURRENT-SHAPING CONTROLLER}

The circuit schematic of the flyback rectifier with the proposed controller is shown in Fig. 1. The variables used in this discussion are also indicated in Fig. 1. The control objective of a single-phase high-power-factor flyback rectifier is to make the input current $i_{g}$ proportional to the full-wave rectified line voltage $v_{g}$, while keeping the output voltage $V_{o}$ regulated at the reference value

$$
i_{g}=\frac{v_{g}}{R_{e}}
$$

$R_{e}$ is the emulated resistance of the rectifier. The desired input voltage and input current waveforms are shown in Fig. 2(a). The flyback rectifier requires input $L_{i}-C_{i}$ filter because current in the primary side of the coupled flyback inductor $L$ is discontinuous. Using duty ratio control continuous current in the $L_{i}$ can be made proportional to the input voltage in each switching pe$\operatorname{riod} T_{s}$. The presence of the input filter has two implications: first, unlike a boost converter, the input voltage to the flyback 


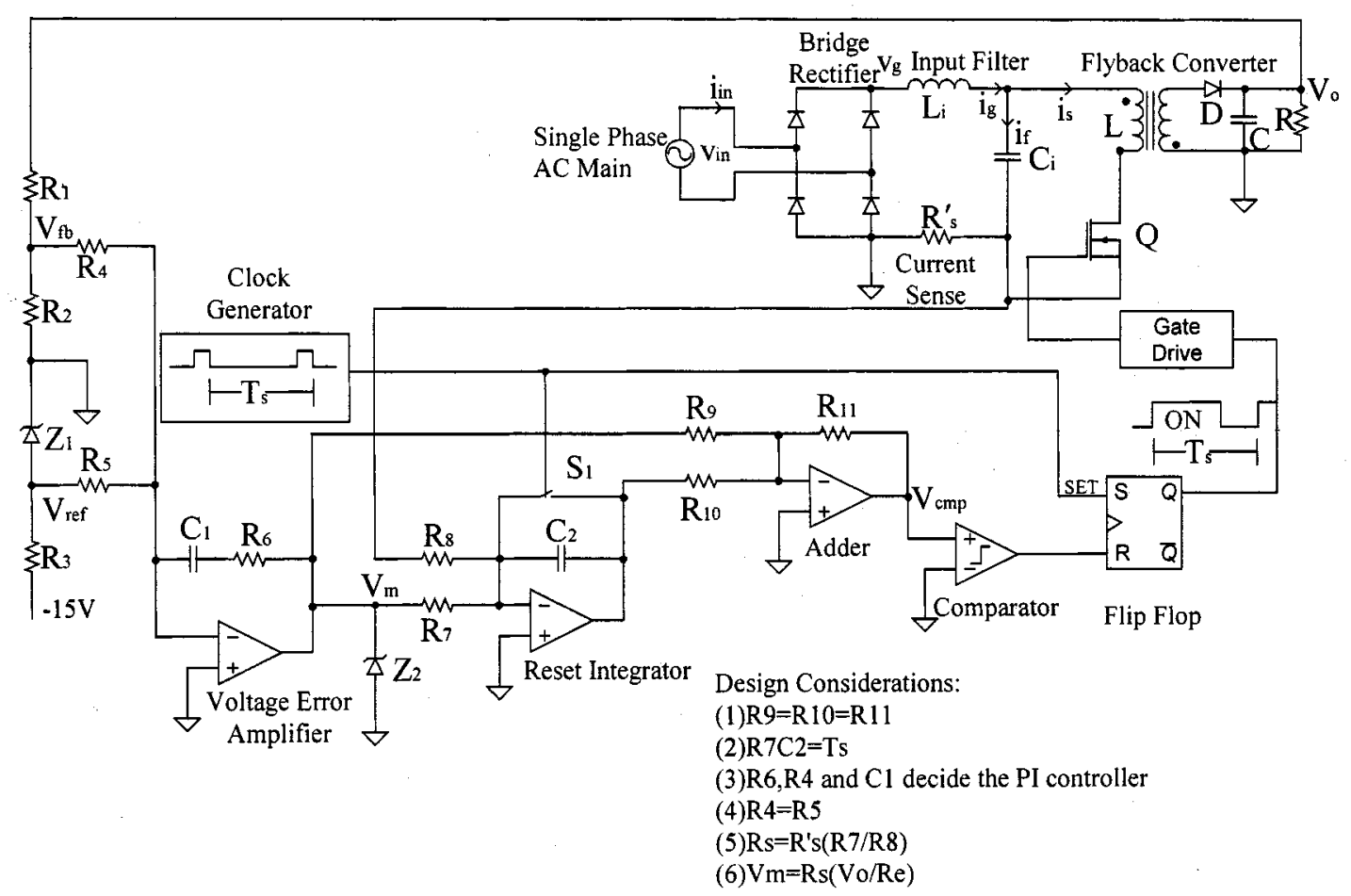

Fig. 1. High-power-factor operation of the flyback rectifier: the proposed controller.

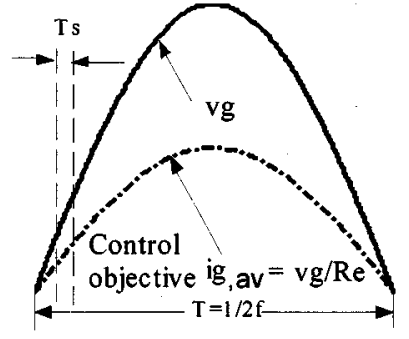

(a)

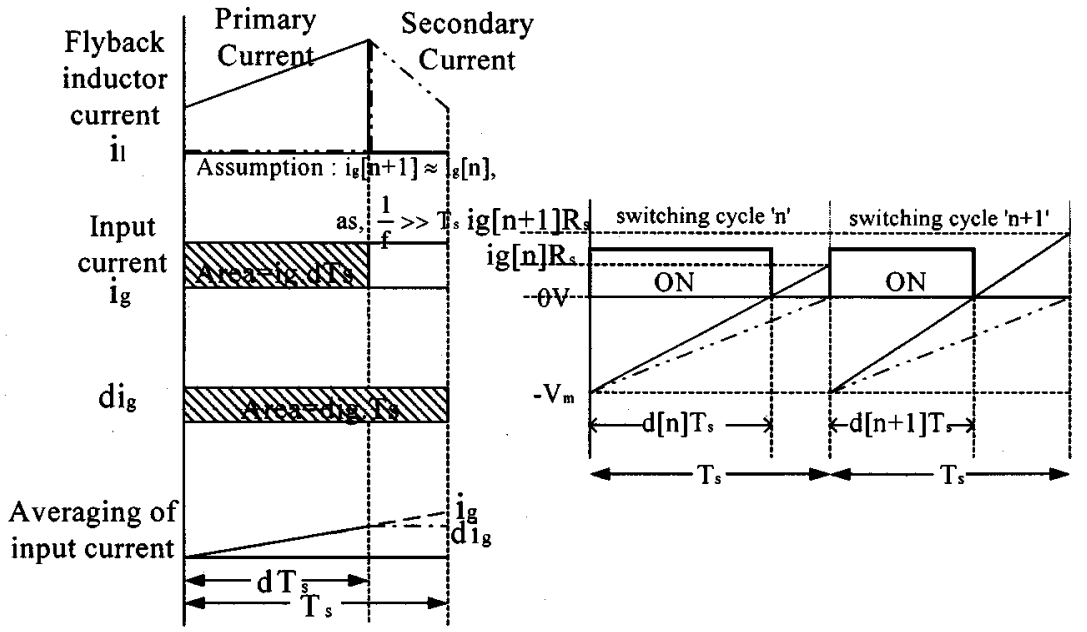

(b) (c)

Fig. 2. Proposed control concept for the high-power-factor flyback rectifier.

converter is $V_{f}$, instead of $V_{g}$. As a consequence, the duty ratio $d$ would vary according to (2) as

$$
d=\frac{V_{o}}{V_{o}+v_{f}}
$$

Here, in order to keep the analysis simple, we have assumed that the flyback inductor turns ratio is 1 . Under quasi-steady-state condition, the duty ratio variation would reflect the variation in $v_{f}$. It is, therefore, necessary that the output impedance of the input filter is designed to be low at line frequency $f$. Then, in (1), $v_{g}$ can be replaced by

$$
v_{g}=\frac{(1-d) V_{o}}{d} .
$$

We, therefore, get

$$
i_{g}=\frac{(1-d) V_{o}}{d R_{e}} .
$$

The second implication of using the input filter is, in each switching period $T_{s}$, the average input current $i_{g, \operatorname{av}\left(T_{s}\right)}$ is 
related to average switch current $i_{s, \operatorname{av}\left(T_{s}\right)}$ and filter capacitor current $i_{f, \operatorname{av}\left(T_{s}\right)}$ as

$$
i_{g, \operatorname{av}\left(T_{s}\right)}=i_{s, \operatorname{av}\left(T_{s}\right)}+i_{f, \operatorname{av}\left(T_{s}\right)} .
$$

For implementing average-current-mode control in shaping the input current, it is convenient to assume that

$$
i_{g, \operatorname{av}\left(T_{s}\right)}=i_{s, \operatorname{av}\left(T_{s}\right)} .
$$

This assumption is made in [1] and [5] and the switch current $i_{s, \text { av }}$ is computed by integration of $i_{s}(t)$ over the ON time of the switch. However, this assumption is not exactly true, as $C_{f}$ has to be charged by $i_{g}$ in each switching period. Particularly near the zero crossing of the line voltage waveform $i_{f, \operatorname{av}\left(T_{s}\right)}$ is substantial compared to $i_{s, \text { av }\left(T_{s}\right)}$. The alternative approach could be to compute $i_{g \text {, av }\left(T_{s}\right)}$, but this cannot be directly used to determine the duty ratio in the same switching period in which the integration needs to be carried out over the entire switching period $T_{s}$. Therefore, we rearrange (4) as

$$
d i_{g, \mathbf{a v}\left(T_{s}\right)}=\frac{(1-d) V_{o}}{R_{e}}
$$

and compute

$$
d i_{g, \operatorname{av}\left(T_{s}\right)}=\frac{1}{T_{s}} \int_{0}^{d T_{s}} i_{g}(t) d t .
$$

Equation (8) is exact if $i_{g}(t)$ is pure dc or dc with triangle-shaped ripple waveform. In this case, we assume that $i_{g}(t)$ during the period $T_{s}$ is constant, as shown in Fig. 2(b).

This is consistent with our previous assumption that the switching frequency is very much higher than the line frequency. We can introduce current-sensing resistance $R_{s}$ in (8) and under closed-loop condition replace the quantities on the right-hand side of (9) by $V_{m}$. $V_{m}$ is the output of the proportional-plus-integral (PI)-type voltage error amplifier

$$
V_{m}=\frac{V_{o} R_{s}}{R_{e}} .
$$

Equations (7)-(9) are combined to formulate (10)

$$
\frac{1}{T_{s}} \int_{0}^{d T_{s}}\left(V_{m}+i_{g} R_{s}\right) d t-V_{m}>0 .
$$

The overall control scheme, as shown in Fig. 1, resembles that of a current-mode control. The switch is turned on at the beginning of every switching period $T_{s}$ and (10) is used to determine the turn-off condition of the switch. The circuit realization of (10) is shown in Fig. 1. It can be seen that a single reset integrator is enough to implement the controller For example, as shown in Fig. 2(c), the modulator produces duty ratios $d[n]$ and $d[n+1]$ in two successive cycles $[n]$ and $[n+1]$ corresponding to input currents $i_{g}[n]$ and $i_{g}[n+1]$, respectively. In principle, the modulator still implements averaged current-mode control as in [1], however, the output of the voltage error amplifier and current sense signals are organized in such a way that there is no conspicuous carrier generated in the implementation and approximation in the carrier waveform is avoided.

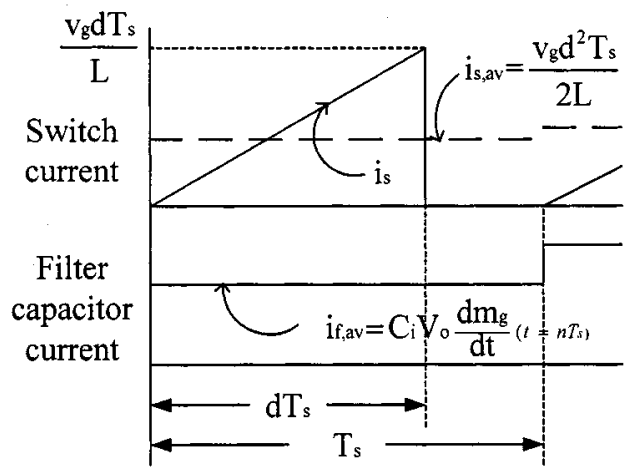

Fig. 3. Switch current and filter capacitor current in a switching period of the flyback inductor operating in DCM.

\section{DCM}

The modulator that generates the switch duty ratio according to (10) will cause the distortion in the input current $i_{g}$ if the flyback rectifier operates in DCM. Then, (3) is no longer valid. Instead,

$$
d<\frac{1}{\left(1+m_{g}\right)}
$$

where

$$
m_{g}=\frac{v_{g}}{V_{o}}
$$

with the assumptions that $v_{g} \approx v_{f}$, and the turns ratio is 1 . The duty ratio of the modulator is determined by

$$
d=\frac{\frac{V_{o}}{R_{e}}}{\frac{V_{o}}{R_{e}}+i_{g, \operatorname{av}\left(T_{s}\right)}} .
$$

In DCM, the flyback inductor primary current is zero at the beginning of the switching period. Therefore, as shown in Fig. 3,

$$
i_{s, \operatorname{av}\left(T_{s}\right)}=\frac{v_{g} d^{2} T_{s}}{2 L} .
$$

Under quasi-steady-state condition,

$$
\left|i_{f, \operatorname{av}\left(T_{s}\right)}\right|=2 \pi f C_{i} V_{o} \sqrt{\left(M_{g}^{2}-m_{g}^{2}\right)}
$$

where

$$
M_{g}=\frac{V_{g m}}{V_{o}} .
$$

$V_{g m}$ is the maximum value of $v_{g}$ over the line cycle. We can replace $i_{g, \operatorname{av}\left(T_{s}\right)}$ in (13) by the expression of (5) and, subsequently, $i_{s, \operatorname{av}\left(T_{s}\right)}$ and $i_{s, \operatorname{av}\left(T_{s}\right)}$ by the expressions of (14) and (15), respectively, to derive the condition for DCM operation from (11) and (14) as

$$
m_{g}<\left(\frac{m_{g}}{\left(1+m_{g}\right)^{2}} \frac{M_{g}^{2}}{2 K_{l}} \pm K_{c} \frac{M_{g}^{2}}{2} \sqrt{M_{g}^{2}-m_{g}^{2}}\right) .
$$

The design parameters $K_{l}$ and $K_{c}$ can be defined as follows:

$$
K_{l}=\frac{2 L}{R T_{s}}
$$


and

$$
K_{c}=2 \pi f R C_{i}
$$

$R$ is the load resistance of the rectifier. The relationship between $R$ and $R_{e}$ can be obtained from the power balance condition between input and output of the flyback rectifier

$$
R_{e}=R \frac{M_{g}^{2}}{2}
$$

Usually, the condition for the DCM operation of a dc-dc converter will be expressed using $K_{l}$, but here it can be seen that $K_{c}$, or the value of the input filter capacitance $C_{i}$, also affects the condition for DCM. Its effect is more pronounced near the positive zero crossing of the input voltage. The inductor will be operating in DCM irrespective of the value of $K_{l}$ and distortion in the line current near positive zero crossing is inevitable. However, if we ignore the term $K_{c}$ in (17), we get (21) as the condition for DCM operation

$$
K_{l}<\frac{M_{g}^{2}}{2\left(1+m_{g}\right)^{2}} .
$$

\section{COMPARISON BETWEEN DCM AND CCM METHOdS OF INPUT CURRENT SHAPING}

It has been shown in [9] that, if the converter is operated in DCM, the input current of the flyback rectifier can be shaped for high-power-factor operation by constant duty ratio control. This method is simple because nothing more than a voltage control loop is required for current shaping, whereas we can see in Fig. 1 that an additional current-mode control loop is required for high-power-factor operation in CCM. In this section, we compare some of the design parameters of the flyback rectifier operating under CCM and DCM methods of input current shaping. The objective is to show some of the disadvantages of DCM operation in order to justify the additional complexity of the CCM structure of current shaping. The design formulas in Table I are approximate, as they are obtained by analysis with simplifying assumptions. The numerical values of the compared parameters are also provided in Table I for the specific example of a 100-W flyback rectifier

$$
\begin{aligned}
V_{\mathrm{in}(\mathrm{rms})} & =70 \mathrm{~V}(\min )-140 \mathrm{~V}(\max ) \\
T_{s} & =20 \mu \mathrm{s} \\
V_{o} & =50 \mathrm{~V} \\
R & =25 \Omega(\min )-100 \Omega(\max ) .
\end{aligned}
$$

The minimum inductance required for CCM over the entire range of input voltage and load conditions can be calculated from (21). The inductance chosen in DCM $(27.6 \mu \mathrm{H})$ is $0.5 \times$ the maximum allowed $(55.2 \mu \mathrm{H})$. The turns ratio is assumed to be 1 .

It can be seen from the expressions of the peak and rms cur-

\begin{tabular}{|c|c|c|}
\hline Parameters & $\mathrm{CCM}$ & DCM \\
\hline $\begin{array}{l}L \\
\text { Flyback inductor }\end{array}$ & $\begin{array}{l}>\left.\frac{R T_{s}}{4} M_{g}^{2}\right|_{\max } \\
>7.84 m H\end{array}$ & $\begin{array}{l}<\left.\frac{R T_{s}}{4} \frac{1}{\left(1+\frac{1}{M_{g}}\right)^{2}}\right|_{\min } \\
<55.2 \mu H\end{array}$ \\
\hline $\begin{array}{l}I_{s_{-}} \text {peak } \\
\text { switch current peak }\end{array}$ & $\begin{array}{l}\left.\frac{2 V_{o}}{R}\left(1+\frac{1}{M_{g}}\right)\right|_{\max } \\
=6.02 \mathrm{~A}\end{array}$ & $\begin{array}{l}\left.2 V_{o} \sqrt{\frac{T s}{R L}}\right|_{\max } \\
=17.03 \mathrm{~A}\end{array}$ \\
\hline $\begin{array}{l}I_{s_{-} r m s} \\
\text { switch current rms }\end{array}$ & $\begin{array}{l}\left.\frac{2 V_{o}}{R} \sqrt{\frac{1}{2 M_{g}^{2}}+\frac{4}{3 \pi M_{g}}}\right|_{\max } \\
=2.34 \mathrm{~A}\end{array}$ & $\begin{array}{l}\left.\frac{2 V_{o}}{\sqrt{3 M_{g}} R^{0.75}}\left(\frac{T_{x}}{L}\right)^{0.25}\right|_{\max } \\
=3.39 \mathrm{~A}\end{array}$ \\
\hline $\begin{array}{l}I_{d_{-} \text {peak }} \\
\text { diode current peak }\end{array}$ & $\begin{array}{l}\left.\frac{2 V_{o}}{R}\left(1+\frac{1}{M_{g}}\right)\right|_{\max } \\
=6.02 \mathrm{~A}\end{array}$ & $\begin{array}{l}\left.2 V_{o} \sqrt{\frac{T_{s}}{R L}}\right|_{\max } \\
=17.02 \mathrm{~A}\end{array}$ \\
\hline $\begin{array}{l}I_{d} \text { rms } \\
\text { diode current rms }\end{array}$ & $\begin{array}{l}\left.\frac{2 V_{o}}{R} \sqrt{\frac{3}{8}+\frac{4}{3 \pi M_{g}}}\right|_{\max } \\
=3.07 \mathrm{~A}\end{array}$ & $\begin{array}{l}\left.1.064 \frac{V_{o}}{R^{0.75}}\left(\frac{T_{s}}{L}\right)^{0.25}\right|_{\max } \\
=4.4 \mathrm{~A}\end{array}$ \\
\hline $\begin{array}{l}I_{c_{-} r m s} \text { output } \\
\text { sapacitor current rms }\end{array}$ & $\begin{array}{l}\left.\frac{2 V_{o}}{R} \sqrt{\frac{1}{8}+\frac{4}{3 \pi M_{g}}}\right|_{\max } \\
=2.33 \mathrm{~A}\end{array}$ & $\begin{array}{l}\frac{V_{o}}{R} \sqrt{1.1 \sqrt{\frac{R T_{s}}{L}}-85 \sqrt{\frac{L}{R T_{s}}}}-\left.\frac{1}{3}\right|_{\text {max }} \\
=4.07 \mathrm{~A}\end{array}$ \\
\hline $\begin{array}{l}D_{\text {min }} \\
\text { minimum duty ratio }\end{array}$ & $\begin{array}{l}\left.\frac{1}{1+M_{g}}\right|_{\min } \\
=0.2\end{array}$ & $\begin{array}{l}\left.\sqrt{\frac{L}{R T_{s}}} \frac{2}{M_{g}}\right|_{\min } \\
=0.06\end{array}$ \\
\hline $\begin{array}{l}I_{s_{-} p e a k}\left(\begin{array}{l}I_{s_{-}} r m s+ \\
I_{d_{-}} r m s\end{array}\right) \\
\text { The quantity on which } \\
\text { area-product design of } \\
\text { the Flyback inductor } \\
\text { depends }\end{array}$ & $\left.\begin{array}{l}\left(\frac{2 V_{o}}{R}\right)^{2}\left(1+\frac{1}{M_{g}}\right) \\
\left(\sqrt{\frac{1}{2 M_{g}^{2}}+\frac{4}{3 \pi M_{g}}}+\right. \\
\sqrt{\frac{3}{8}+\frac{4}{3 \pi M_{g}}}\end{array}\right)\left.\right|_{\max }$ & $\begin{array}{l}\left(\frac{2}{\sqrt{3 M_{g}}}+1.064\right) \\
\left(\frac{2 V_{0}}{\sqrt{R}} \sqrt{\frac{T_{s}}{L}}\right) \\
\frac{V_{o}}{R^{0.75}}\left(\frac{T_{s}}{L}\right)^{0.25} \\
=132.62 A^{2}\end{array}$ \\
\hline
\end{tabular}
rents of the switch and the diode that in the DCM flyback inductor $L$ appears in the denominator. Therefore, to reduce the conduction and switching losses in the semiconductor devices, the flyback inductance should be made as high as possible. Sim-
TABLE I

DESIGN PARAMETERS IN CCM AND DCM

ilarly, the rms current rating of the output capacitance is minimum when the inductance is maximum. The flyback rectifier will have lower efficiency in the DCM compared to the CCM. The requirement of minimum duty ratio in the DCM is shown to be a function of the inductance. It can be so low as to cause some difficulty in circuit realization. However, even if we limit the range of CCM in a practical design, compared to the DCM, we need a much higher value of flyback inductor in the CCM. However, their sizes are not in the same proportion as the inductance values because in the area-product design of the inductor we have to also take into account the quantity given by $I_{s_{-} \text {peak }}\left(I_{s_{-} \text {rms }}+I_{d_{-} \text {rms }}\right)$. This quantity is a function of $L$ in the DCM and higher than the corresponding value in the CCM operation. For these reasons, it has been observed in [1] that, at higher power levels, CCM of operation is preferred. The DCM operation also increases the size and weight of the electromagnetic interference (EMI) filter [3]. 


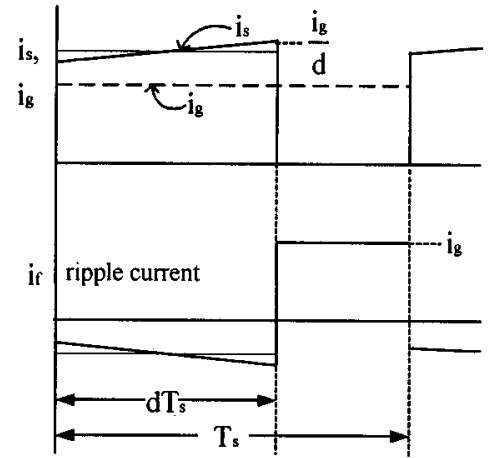

(a)

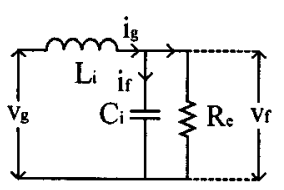

(b)

Fig. 4. Input filter design considerations.

\section{INPUT FILTER DESIGN}

Let us define the condition for the selection of $C_{i}$ as, if in a line cycle,

$$
m_{g} \geq m_{g c}=N M_{g}
$$

then the flyback inductor should be in CCM. $N$ has to be chosen as a design parameter

$$
N=\frac{v_{g c}}{V_{g m}}
$$

where $v_{g c}$ is the critical input voltage above which we want the converter to operate in CCM. For $m_{g c} \approx 0$, we can approximate $\left(1+m_{g}^{2}\right)$ as 1 and $M_{g}^{2}-m_{g}^{2}$ as $M_{g}^{2}$ in (17)

$$
C_{i}<\frac{N\left(1-\frac{M_{g}^{2}}{2 K_{l}}\right)}{\frac{M_{g}^{2}}{2}(2 \pi f R)} .
$$

However, in a practical design the actual value of $C_{i}$ will also be determined by the rms value of the ripple current requirement of the circuit. The switch current $i_{s}$, input current $i_{g}$, and the filter capacitor current $i_{f}$ in a switching period $T_{s}$ can be approximated as shown in Fig. 4(a). In a switching period in which the input voltage is $v_{g}$, the ripple current through $C_{i}$ can be computed as

$$
i_{f, \mathrm{rms}\left(T_{s}\right)}=\sqrt{\left(\frac{i_{g}}{d}-i_{g}\right)^{2} d+i_{g}^{2}(1-d)}=\frac{v_{g}}{R_{e}} \sqrt{m_{g}} .
$$

The rms current rating of $C_{i}$ over the line half cycle as

$$
I_{f, \mathrm{rms}}=\frac{4 V_{o}}{\sqrt{3 \pi M_{g}} R} .
$$

The lower limit of the filter inductance $L_{i}$ can be determined from the condition that the input filter time constant should be greater that $\alpha(>4)$ times the switching period $T_{s}$. We should also make sure that the phase difference between $v_{g}$ and $v_{f}$ at line frequency is not substantial so that our assumption $v_{g} \approx v_{f}$ remains valid. The simplified equivalent circuit of Fig. 4(b) is

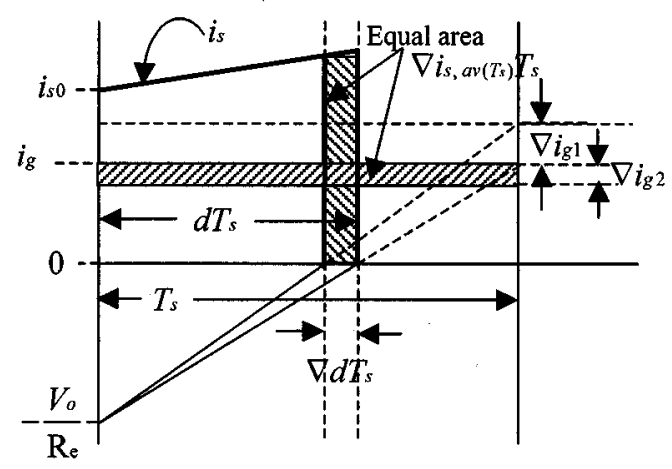

Fig. 5. Graphical analysis of steady-state stability condition.

used to derive the upper limit of $L_{i}$. These two conditions are given by (27) and (28), respectively,

$$
\begin{aligned}
& L_{i}>\left(\frac{\alpha T_{s}}{2 \pi}\right)^{2} \frac{1}{C_{i}} \\
& L_{i}<\frac{\beta R}{f}
\end{aligned}
$$

where

$$
\beta=\frac{\tan (\theta) M_{g}^{2}}{4 \pi}
$$

and $\theta$ is to be chosen by the designer as the maximum phaseangle difference between $v_{g}$ and $v_{f}$ at line frequency. Equations (24) and (26)-(28) help us in selecting the input filter components.

\section{Steady-State Stability CONDition}

The steady-state stability analysis presented in this section is graphical in nature. We have followed the same method that has been used in [6] for deriving the steady-state stability condition for the current-mode-controlled dc-dc converter. The objective here is to quantify the steady-state stability condition of the flyback rectifier in terms of circuit parameters and switching frequency of the converter.

In a switching period $T_{s}, i_{g}$ has no significant turn-on or turn-off slope, because $v_{g} \approx v_{f}$. So, it can be assumed that the current in the input filter inductor is constant in that period, therefore, $i_{g, \operatorname{av}\left(T_{s}\right)}=i_{g}$. As a result, the input filter inductor does not appear as a parameter in the steady-state stability analysis of the flyback rectifier. Further, it is shown in (15) that $i_{f, \operatorname{av}\left(T_{s}\right)}$ is a function of only one variable $v_{g}$ and $v_{g}$ is almost constant in a switching period $T_{s}$, therefore, $\nabla i_{f, \operatorname{av}\left(T_{s}\right)}=0$, and (30) can be obtained by perturbation of (5)

$$
\nabla i_{g}=\nabla i_{s, \operatorname{av}\left(T_{s}\right)}
$$

Therfore, the input filter capacitance has no impact on the condition derived for steady-state stability. Let $\nabla i_{g 1}$ be the initial perturbation in $i_{g}$ and at the end of the switching period the perturbation becomes $\nabla i_{g 2}$, as shown in Fig. 5. From the modulator 
equation of (7), $\nabla d$, the perturbation in the duty ratio caused by $\nabla i_{g 1}$, can be computed as

$$
\nabla d=\frac{-d}{i_{g}+\frac{V_{o}}{R_{e}}} \nabla i_{g 1}
$$

Let us express $i_{s, \operatorname{av}\left(T_{s}\right)}$ as

$$
i_{s, \operatorname{av}\left(T_{s}\right)}=K_{1} d+K_{2} d^{2}
$$

where, as shown in Fig. 5,

$$
K_{1}=i_{s 0} \quad \text { and } \quad K_{2}=\frac{v_{g} T_{s}}{2 L} .
$$

The perturbation in $i_{s, \operatorname{av}\left(T_{s}\right)}$, denoted as $\nabla i_{s, \operatorname{av}\left(T_{s}\right)}$, can be expressed as

$$
\nabla i_{s, \text { av }\left(T_{s}\right)}=\left(K_{1}+2 K_{2} d\right) \nabla d .
$$

Therefore, combining (30), (31), and (34), we get

$$
\frac{\nabla i_{g 2}}{\nabla i_{g 1}}=\left(K_{1}+2 K_{2} d\right) \frac{-d}{\left(i_{g}+\frac{V_{o}}{R_{e}}\right)} .
$$

In order to keep the analysis simple, here, we ignore the effect of $i_{f, \operatorname{av}\left(T_{s}\right)}$ on $i_{g}$, then $d i_{s 0}$ can be expressed as

$$
d i_{s 0}=i_{g}-\frac{1}{2} \frac{d^{2} v_{g} T_{s}}{L} .
$$

Subharmonic oscillations in the flyback rectifier can be avoided under the following condition:

$$
\left|\frac{\nabla i_{g 2}}{\nabla i_{g 1}}\right|<1
$$

Using the expressions of (33), (35), (36), (3), and (20) in (37), the steady-state stability condition can be quantified in terms of design elements as

$$
\frac{2 L}{R T_{s}}>K_{s}
$$

where

$$
K_{s}=\frac{M_{g}^{2}}{2}(1-d) d .
$$

In a line half cycle, $K_{s}$ is maximum in the switching period in which $d$ is 0.5 or $v_{g}=V_{o}$. Therefore, the steady-state stability criteria for the flyback rectifier is fulfilled over the entire line half cycle if (40) is satisfied

$$
\frac{2 L}{R T_{s}}>\frac{M_{g}^{2}}{8} .
$$

By putting $m_{g}=0$ in (21), we get the condition for the flyback rectifier to operate in $\mathrm{CCM}$ over the entire line half cycle

$$
\frac{2 L}{R T_{s}}>\frac{M_{g}^{2}}{2} \text {. }
$$

From (40) and (41), we conclude that the flyback rectifier, which operates in CCM over the entire line half cycle, cannot have the steady-state stability problem.

\section{SABER Simulation}

A $100-\mathrm{W}$ output $110-\mathrm{V}$ ac (rms) input $50-\mathrm{V}$ dc output flyback rectifier is simulated using the SABER circuit simulator package. The simulation results of a few important circuit waveforms are shown in Fig. 6.

The following components are used for the simulation of the flyback rectifier:

$$
\begin{aligned}
L_{i} & =110 \mu \mathrm{H} \\
C_{i} & =2 \mu \mathrm{F} \\
L_{p} & =5.5 \mathrm{mH} \\
L_{s} & =5.5 \mathrm{mH} \\
C & =4400 \mu \mathrm{F} \\
R & =25 \Omega \\
R_{s}^{\prime} & =0.5 \Omega \\
R_{7} C_{2} & =20 \mu \mathrm{s} \\
Q & =\text { MTW20N50E } \\
D & =\text { MUR } 460 \\
\frac{R_{7}}{R_{8}} & =\frac{2000}{470} .
\end{aligned}
$$

\section{SMALl-Signal Low-FreQuency Model}

In this section, we would like to develop a linear low-frequency small-signal model of the flyback rectifier. In a line cycle, the input voltage $v_{g}$ varies from 0 to $V_{g m}$ and under steady-state condition the input current $i_{g}$ is proportional to input voltage and the volt-second balance for the Flyback inductor occurs at every switching period $T_{s}$.

However, the instantaneous input power $v_{g} i_{g}$ equals the output power $V_{0}^{2} / R$ only at the period in which the input voltage is $V_{g m} / \sqrt{2}$. We therefore choose this switching period as the equivalent nominal operating point that represents the entire line cycle for the derivation of the small-signal model. The variables are expressed by capital letters (nominal as well as dc) and small-signal deviations by $\left(^{\wedge}\right)$ on the top of the symbol. The control structure shown in Fig. 1 is that of a current-mode controller. Therefore, the control gain transfer function is derived in two steps [6]. First, the low-frequency small-signal model of the flyback converter is obtained in the standard form in terms of duty ratio perturbation $\hat{D}$ as the control input. Subsequently, the small-signal model of the modulator is derived to replace the $\hat{D}$ term in the converter model by the perturbations in the error amplifier output voltage $\hat{V}_{m}$ and other state variables $\hat{V}_{o}$ and $\hat{I}_{l}$. The output impedance of the input filter is assumed to be low and its effect on the voltage control transfer function is ignored. The state-variable description of the converter is given by (42)

$$
\left[\begin{array}{l}
L \frac{d I_{l}}{d t} \\
C \frac{d V_{o}}{d t}
\end{array}\right]=\left[\begin{array}{cc}
0 & -(1-D) \\
(1-D) & -\frac{1}{R}
\end{array}\right]\left[\begin{array}{l}
I_{l} \\
V_{o}
\end{array}\right]+\left[\begin{array}{c}
D \\
0
\end{array}\right]\left[V_{g}\right]
$$




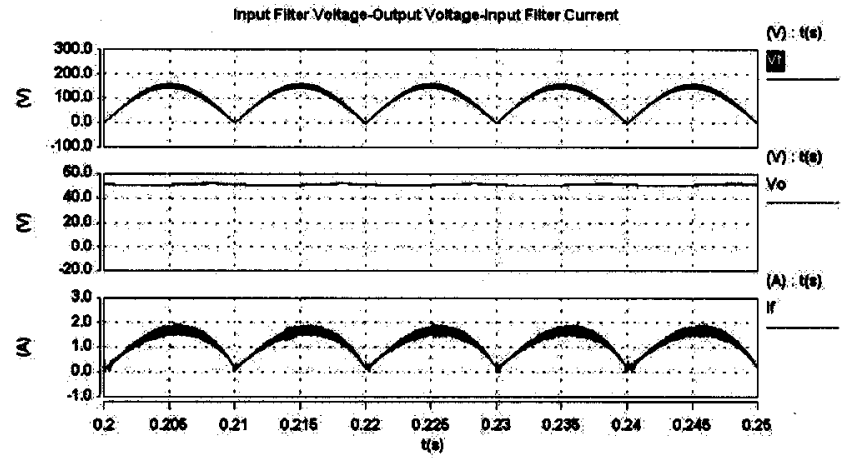

(a)

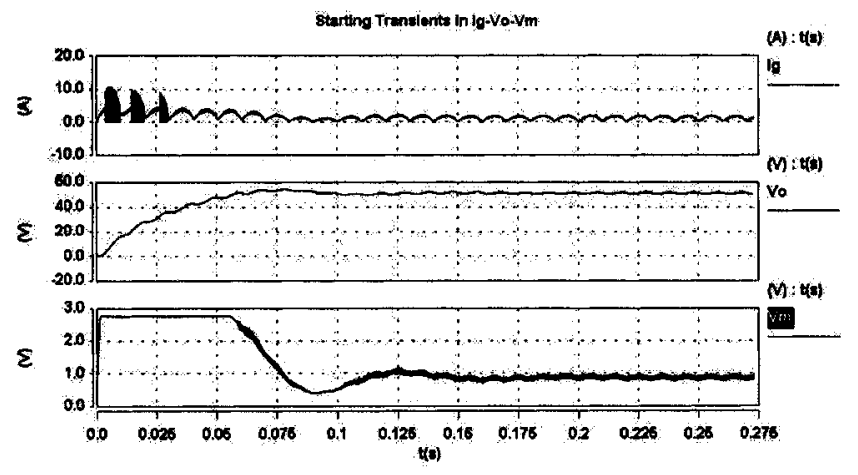

(c)

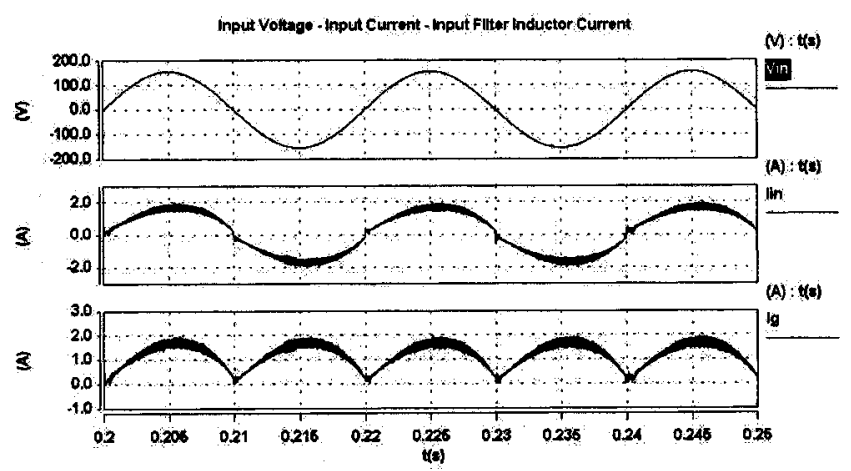

(b)

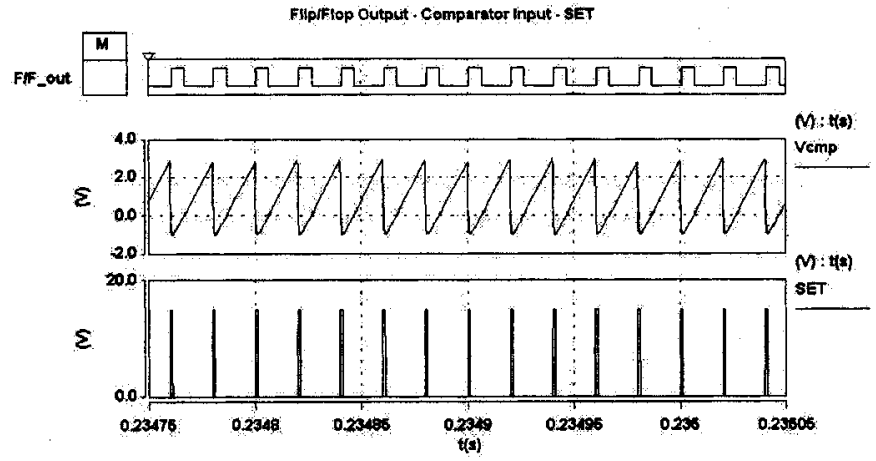

(d)

Fig. 6. Simulation results from SABER. (a) Filter capacitor voltage, output voltage, and filter inductor current. (b) Input voltage, input current, and filter inductor current. (c) Startup transient of filter inductor current, output voltage, and error amplifier output voltage. (d) Switching pulses from flip/flop output, LM339 input voltage, and periodic set pulses to the flip/flop.

where

$$
V_{g}=\frac{V_{g m}}{\sqrt{2}}
$$

The steady state values of $V_{o}$ and $I_{l}$ can be obtained from (44) and (45)

$$
\begin{aligned}
V_{o} & =\frac{D}{1-D} V_{g} \\
I_{l} & =\frac{D V_{g}}{(1-D)^{2} R} .
\end{aligned}
$$

The linear small-signal model of the flyback converter is obtained by perturbing the state variables and the duty ratio input. Since our objective is to derive the control transfer function $G_{v}(s)$, the input voltage $V_{g}$ is not perturbed

$$
\left[\begin{array}{c}
L \frac{d \hat{I}_{l}}{d t} \\
C \frac{d \hat{V}_{o}}{d t}
\end{array}\right]=\left[\begin{array}{cc}
0 & -(1-D) \\
(1-D) & -\frac{1}{R}
\end{array}\right]\left[\begin{array}{l}
\hat{I}_{l} \\
\hat{V}_{o}
\end{array}\right]+\left[\begin{array}{c}
V_{g}+V_{o} \\
-I_{l}
\end{array}\right] \hat{D} .
$$

The modulator uses the input current $I_{g}$ for producing the duty ratio of the period

$$
D=1-\frac{I_{g} R_{s}}{V_{m}}
$$

We need to express $I_{g}$ as a function of $I_{l}, V_{o}$, and $V_{g}$, as $I_{g}$ is not a variable used in (42). We should not use (44) to express $I_{g}$ in terms of $D$, as $D$ is the output variable of the modulator

$$
I_{g}=\frac{V_{o}}{R} \frac{\sqrt{2}}{M_{g}}=\frac{\sqrt{2}}{M_{g}} \frac{1}{\left(1+\frac{\sqrt{2}}{M_{g}}\right)} I_{l}=\frac{V_{o}}{V_{g}+V_{o}} I_{l} .
$$

The modified form of the modulator equation is given by (49)

$$
V_{m}\left(V_{o}+V_{g}\right)=D\left[V_{m}\left(V_{o}+V_{g}\right)+V_{o} I_{l} R_{s}\right] .
$$

The steady-state value of $D$ can be obtained by solving (50)

$$
\left(1+\frac{V_{g}}{V_{m}} \frac{R_{s}}{R}\right) D^{3}-3 D^{2}+3 D-1=0 .
$$

We perturb (49) and subsequently linearize the quantities to obtain the small-signal linear model of the modulator as given by (51)

$$
\begin{aligned}
\left(V_{g} V_{m}+\right. & \left.V_{m} V_{o}+V_{o} I_{l} R_{s}\right) \hat{D}+\left(V_{g} D+V_{o} D-V_{g}-V_{o}\right) \hat{V}_{m} \\
& +\left(V_{m} D+I_{l} R_{s} D-V_{m}\right) \hat{V}_{o}+V_{o} D R_{s} \hat{I}_{l}=0 .
\end{aligned}
$$

We define the constants $K_{1}, K_{2}, K_{3}$, and $K_{4}$ as follows:

$$
\begin{aligned}
K_{1} & =V_{g} V_{m}+V_{m} V_{o}+V_{o} I_{l} R_{s} \\
& =\frac{V_{g} V_{m}}{(1-D)}+\frac{D^{2} V_{g}^{2}}{(1-D)^{3}} \frac{R_{s}}{R} \\
K_{2} & =-\left(V_{g}+V_{o}\right)(1-D)=-V_{g}
\end{aligned}
$$




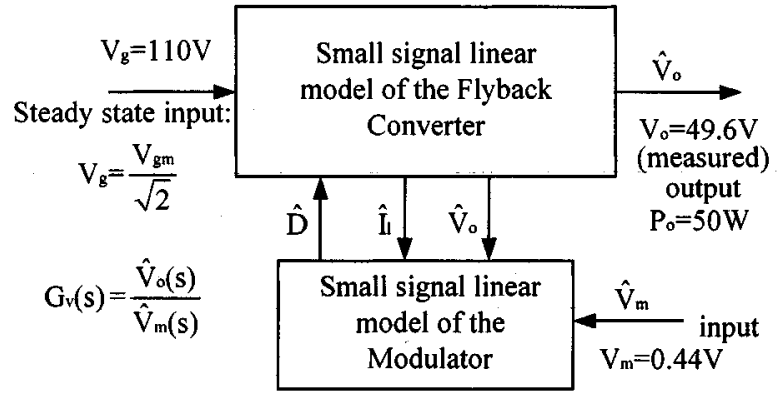

Fig. 7. Derivation of the low-frequency small-signal linear model of the flyback rectifier switched by the input current-shaping modulator described by (47).

$$
\begin{aligned}
K_{3} & =-V_{m}(1-D)+I_{l} R_{s} D \\
& =-V_{m}(1-D)+\frac{D^{2} V_{g}}{(1-D)^{2}} \frac{R_{s}}{R} \\
K_{4} & =V_{o} R_{s} D=\frac{D^{2} V_{g} R_{s}}{(1-D)}
\end{aligned}
$$

and rewrite (46) as (54), shown at the bottom of the page, after replacing $\hat{D}$ by the expression of (53), also shown at the bottom of the page. The control gain $G_{v}(s)$ can be obtained as

$$
G_{v}(s)=\frac{\hat{V}_{o}(s)}{\hat{V}_{m}(s)}=\frac{N_{m}(s)}{D_{m}(s)} .
$$

The numerator and denominator polynomials are expressed as

$$
\begin{aligned}
N_{m}(s)= & \frac{D}{(1-D)^{2}} \frac{V_{g}}{R} \frac{K_{2}}{K_{1}} L s-V_{g} \frac{K_{2}}{K_{1}} \\
D_{m}(s)= & {\left[\frac{K_{3}}{K_{1}}(1-D)+\frac{1}{R} \frac{K_{4}}{K_{1}}\right] \frac{V_{g}}{(1-D)} } \\
& +(1-D)\left[1-D+\frac{D}{(1-D)^{2}} \frac{V_{g}}{R} \frac{K_{4}}{K_{1}}\right] \\
& +s\left[C \frac{K_{4}}{K_{1}} \frac{V_{g}}{(1-D)}+\frac{L}{R}-\frac{K_{3}}{K_{1}} \frac{D}{(1-D)^{2}} \frac{V_{g}}{R} L\right] \\
& +s^{2} L C .
\end{aligned}
$$

The analytical model developed in this section is valid at any input-output and load condition as long as the flyback converter operates in the CCM. For validation of the developed low-frequency small-signal model, the nominal operating point of Fig. 7 is chosen. The component values of the experimental flyback rectifier unit are $L=5.5 \mathrm{mH}, C=4400 \mu \mathrm{F}, R=$ $50 \Omega$, and $R_{s}=2.13 \Omega$. Fig. 8 shows the Bode plot of $G_{v}(s)$,
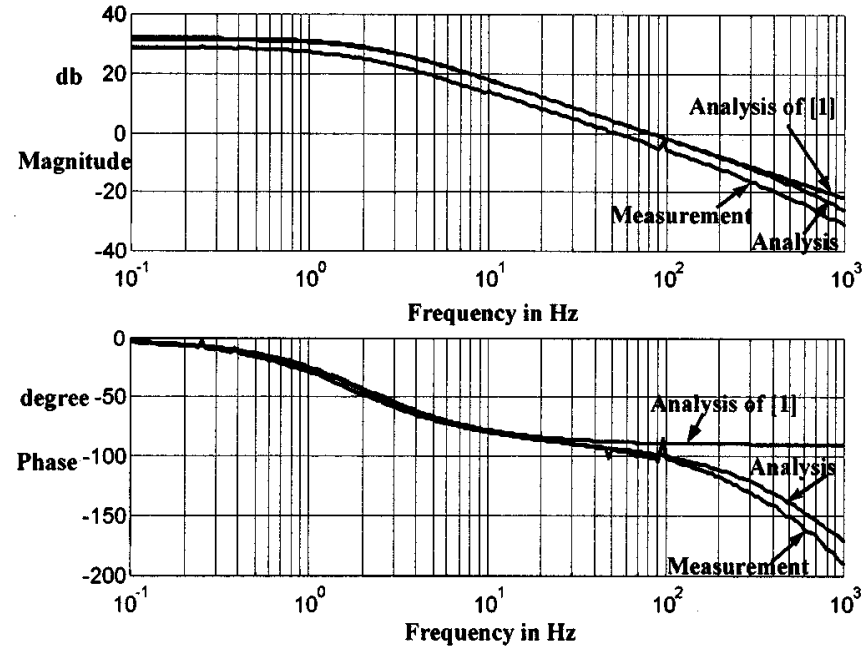

Fig. 8. Bode plot of the control transfer function.

which is obtained by analysis. The measurement results of the control transfer function are obtained from the flyback rectifier experimental unit by using a Schlumberger 1250 Frequency Response Analyzer. These results are placed in the same figure for easy comparison. The dc input voltage for the modulator $\left(V_{m}=0.44 \mathrm{~V}\right)$ is chosen so as to obtain the rated output voltage $(50 \mathrm{~V})$ at half the maximum load $(50 \mathrm{~W})$, at nominal input voltage $(110 \mathrm{~V})$ condition

$$
V_{m}=\frac{2 V_{o} R_{s}}{M_{g}^{2} R}=\frac{2.50 .2 .13}{\left(\frac{110 \sqrt{2}}{50}\right)^{2} 50} V=0.44 \mathrm{~V} .
$$

It can be seen that, qualitatively, the analysis and measurement results match each other very closely. The dc shift in magnitude plot is due to the reason that, in the analysis, the nonidealities that contribute to losses were not considered. This validates our choice of $V_{g m} / \sqrt{2}$ as the nominal operating point in a cycle of the input voltage waveform. A closed-loop controller for the outer voltage loop can now be designed from the analytical model given by (55)-(57), using the standard method available in linear control theory.

It has been assumed that, in a switching period $T_{s}$, the current $i_{g}$ in the filter inductor is constant (Fig. 2). The slope required in the modulator for the generation of the duty ratio $d$ is obtained by integration of $i_{g}$. As a result, $L_{i}$ does not appear as a parameter in the small-signal model of the modulator given by (51). In the basic flyback converter model, additional state-space equations could have been written using input filter components. However, the resonant frequency of the input filter is so high that

$$
\begin{aligned}
& \hat{D}=-\frac{K_{2}}{K_{1}} \hat{V}_{m}-\frac{K_{3}}{K_{1}} \hat{V}_{o}-\frac{K_{4}}{K_{1}} \hat{I}_{l} \\
& {\left[\begin{array}{c}
L \frac{d \hat{I}_{l}}{d t} \\
C \frac{d \hat{V}_{o}}{d t}
\end{array}\right]=\left[\begin{array}{cc}
-\frac{V_{g}}{(1-D)} \frac{K_{4}}{K_{1}} & -(1-D)-\frac{V_{g}}{(1-D)} \frac{K_{3}}{K_{1}} \\
1-D+\frac{D V_{g}}{(1-D)^{2} R} \frac{K_{4}}{K_{1}} & -\left(\frac{1}{R}-\frac{K_{3}}{K_{1}} \frac{D V_{g}}{(1-D)^{2} R}\right)
\end{array}\right]\left[\begin{array}{c}
\hat{I}_{l} \\
\hat{V}_{o}
\end{array}\right]+\left[\begin{array}{c}
-\frac{V_{g}}{(1-D)} \frac{K_{2}}{K_{1}} \\
\frac{D}{(1-D)^{2}} \frac{V_{g}}{R} \frac{K_{2}}{K_{1}}
\end{array}\right]\left[\hat{V}_{m}\right] }
\end{aligned}
$$




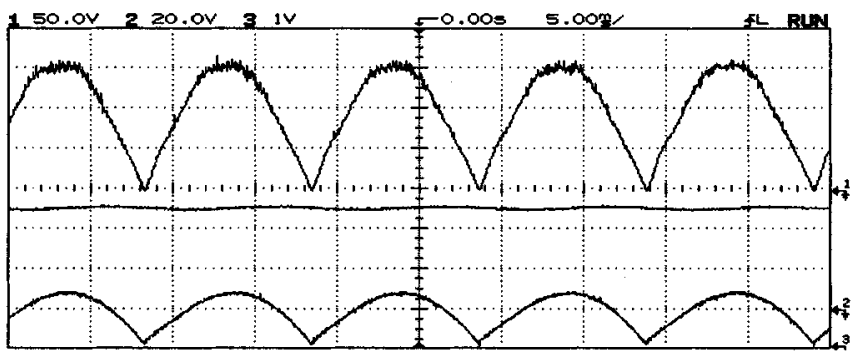

(a)

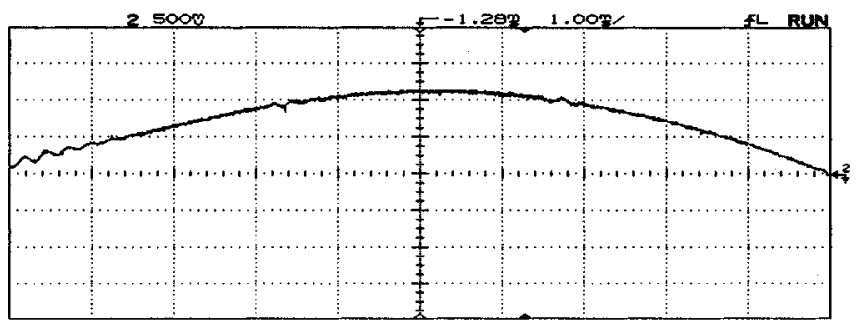

(c)

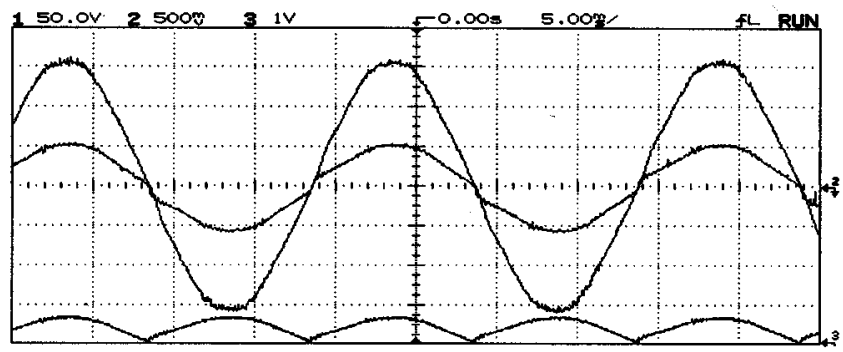

(e)

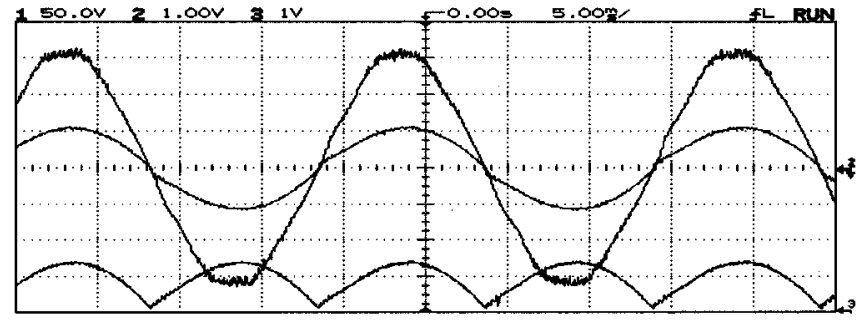

(b)

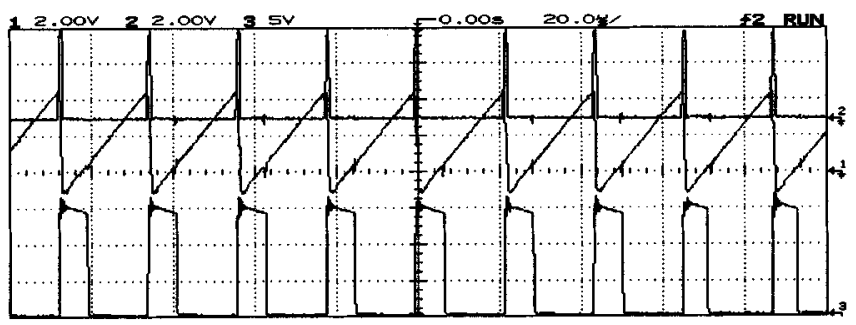

(d)

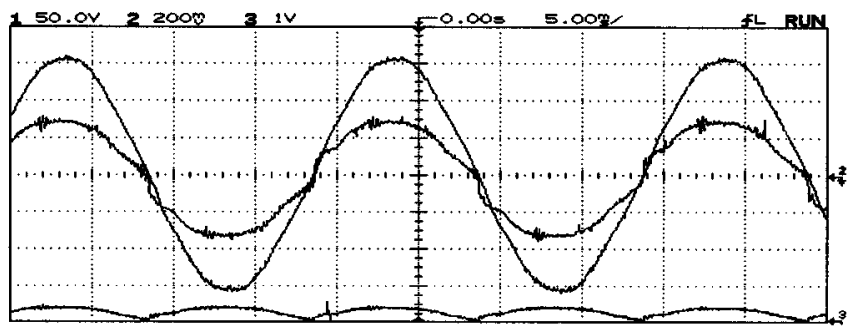

(f)

Fig. 9. Experimental results. (a) Filter capacitor voltage ( $50 \mathrm{~V} / \mathrm{div})$, dc output voltage ( $20 \mathrm{~V} / \mathrm{div})$, and filter inductor current ( $1 \mathrm{~A} / \mathrm{div})$ at $100 \mathrm{~W}$. (b) Input voltage $(50 \mathrm{~V} / \mathrm{div})$, input current $(1.5 \mathrm{~A} / \mathrm{div})$, and filter inductor current $(1 \mathrm{~A} / \mathrm{div})$. (c) Distortion in input filter current near positive zero crossing. (d) Periodic set pulse, LM339 input, SR F/F output. (e) Input voltage (50 V/div), input current $(0.75 \mathrm{~A} / \mathrm{div})$, and filter inductor current (1 A/div) at 50-W output. (f) Input voltage (50 $\mathrm{V} /$ div), input current $(0.3 \mathrm{~A} / \mathrm{div})$, and filter inductor current $(1 \mathrm{~A} / \mathrm{div})$ at $25-\mathrm{W}$ output.

it is beyond the frequency range of interest necessary for the design of the voltage error amplifier. For example, the closed-loop crossover frequency can be chosen as $10 \mathrm{~Hz}$, as suggested in [1], the resonant frequency of the input filter components used in this implementation is $10.7 \mathrm{kHz}\left(L_{i}=110 \mu \mathrm{H}, C_{i}=2 \mu \mathrm{F}\right)$, and the frequency range of the model developed and validated in this paper is $1 \mathrm{kHz}$. It is also assumed that the output impedance of the input filter is low compared to the input impedance of the basic converter. Therefore, the input filter components do not have any effect on the stability condition of the flyback converter [8]. For these reasons, the input filter components are not included in the small-signal low-frequency model of the flyback rectifier.

The small-signal model of [1] is developed using the Power Output $=$ Power Input (POPI) concept [7]. The control gain transfer function of [1] is first order, which can effectively be used to design the frequency response of the voltage error amplifier. Usually, for the power-factor-correction circuit, the closed-loop bandwidth is chosen around 5-10 Hz. Therefore, the small-signal model developed here, even though accurate for higher frequency of operation compared to [1], has no added advantage as far as the design of the closed-loop controller is concerned. However, this model has been derived following the standard technique used by power supply designers in determining the small-signal model of a current-mode-controlled dc-dc converter. It is shown here that, with proper choice of the nominal operating point in a line cycle, a second-order model of the flyback rectifier can be obtained. This model equates the frequency response of the model in [1] in the low-frequency range, as shown in Fig. 8. It may also be noted that the derivation of the small-signal model need not be performed manually because standard computer-aided design tools are nowadays available for small-signal analysis of $\mathrm{dc}-\mathrm{dc}$ converters.

\section{EXPERIMENTAL VERIFICATION}

The simulation results obtained from the SABER package show the validity of the control concept. It has been further confirmed by hardware implementation of a 100-W flyback rectifier 
with the same component values as used in the SABER simulation. The experimental results are presented in Fig. 9. These results match the SABER results very closely. The total harmonic distortion of the line current is found to be less than $4 \%$ over a load range of 25-100 W.

\section{CONCLUSION}

A simple but high-performance resistor-emulator-type inputcurrent-shaping controller for high-power-factor operation of a flyback rectifier has been proposed in this paper. Input voltage sensing is not required and a multiplier is not used in implementation. The proposed method eliminates the need for approximating the carrier waveform; instead, a single reset integrator is used to integrate the combined signal obtained from the input current sense and output of the voltage error amplifier. The analysis presented in this paper has shown the effect of the filter capacitor on the range of DCM operation of the flyback inductor current. Design equations were formulated for selection of the input filter components. It has been shown that the flyback rectifier cannot have the steady-state stability problem if it is operated in the CCM over the entire line half cycle. The performance of the controller has been verified in SABER. A small-signal low-frequency model of the flyback rectifier was derived by perturbing the converter states and inputs at the nominal operating point of input voltage rms. Measurement results of $G_{v}(s)$ validate the analytical model. The controller has been tested in hardware by building a $100-\mathrm{W}$ flyback rectifier prototype unit. The experimental and SABER results match each other very closely. Very low total harmonic distortion of the input current has been obtained over a wide range of loads.

\section{REFERENCES}

[1] R. Zane and D. Maksimovic, "Nonlinear-carrier control for high power factor rectifiers based on up-down switching converters," IEEE Trans. Power Electron., vol. 13, pp. 213-221, Mar. 1998.

[2] R. Mammano and R. Neidorff, "Improving input power factor-A new active controller simplifies the task," in Proc. Power Conversion Conf., Oct. 1989 , pp. 100-109.

[3] W. Tang, Y. Jiang, G. C. Hua, and F. C. Lee, "Power factor correction with flyback converter employing charge control," in Proc. IEEE APEC'93, 1993, pp. 293-298.

[4] S. Buso, G. Spiazzi, and D. Taglivia, "Simplified control technique for high-power-factor Flyback Cuk and Sepic rectifiers operating in CCM," in Conf. Rec. IEEE-IAS Annu. Meeting, vol. 3, 1999, pp. 1633-1638.
[5] Z. Lai and K. Ma. Smedley, "A family of continuous-conduction-mode power-factor-correction controllers based on the general pulse-width modulator," IEEE Trans. Power Electron., vol. 13, pp. 501-510, May 1998.

[6] R. D. Middlebrook, "Topics in multiple-loop regulators and current-mode programming," IEEE Trans. Power Electron., vol. PE-2, pp. 109-124, Apr. 1987.

[7] S. Singer and R. Erickson, "Canonical modeling of power processing circuits based on the POPI concept," IEEE Trans. Power Electron., vol. 7, pp. 37-43, Jan. 1992.

[8] R. D. Middlebrook, "Input filter considerations in design and application of switching regulators," in Conf. Rec. IEEE-IAS Annu. Meeting, Chicago, IL, Oct. 11-14, 1976, pp. 366-382.

[9] R. Erickson, M. Madigan, and S. Singer, "Design of a simple highpower-factor rectifier based on the flyback converter," in Proc. IEEE APEC'90, 1990, pp. 792-801.

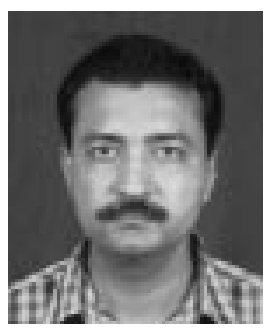

Souvik Chattopadhyay received the B.E. degree from Bengal Engineering College, Howrah, India, and the M.Sc. (Engg.) degree from Indian Institute of Science, Bangalore, India, in 1988 and 1990, respectively, both in electrical engineering with a specialization in power electronics. He is currently working toward the Ph.D. degree in the Power Electronics Laboratory, Department of Electrical Engineering, Indian Institute of Science.

Between 1991-1995, he was with M/s Crompton Greaves Ltd., Bombay, India, as a Research and Development Engineer in the Power Electronics Group of R\&D (Electricals). Between 1996-1998, he was with M/s Cegelec India Ltd., Delhi, India, as a Project Engineer-Industrial Drives. He was a part of the commissioning team for phase IV modernization of the TISCO Hot Strip Mill, Jamshedpur, India. His research interests include design, analysis, control, and modeling of power converters for PFC circuits and active filter systems.

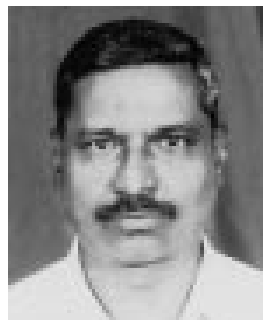

V. Ramanarayanan received the B.E. degree from the University of Madras, Madras, India, the M.E. degree from Indian Institute of Science, Bangalore, India, and the Ph.D. degree from California Institute of Technology, Pasadena, in 1970, 1975, and 1986, respectively.

$\mathrm{He}$ is a Professor and Chairman of the Department of Electrical Engineering, Indian Institute of Science. He had held positions in industry as a Senior Design Engineer and Chief of R\&D with M/s Larsen and Toubro Ltd. (1970-1979) and NGEF Ltd. (1979-1982). His areas of interest include power electronics, industrial drives, switched-mode power conversion, and power quality issues. He is a Consultant to several industries in related areas. 